\title{
A Comparative Study and Association between Depression and Male Infertility
}

\author{
Pratiti Pattnaik $^{1 *}$, Sarat Chandra Gharai ${ }^{2}$, Narendranath Samantaray ${ }^{3}$
}

\begin{abstract}
Introduction- Infertility affects both male and female. Little attention has been given to the psychological status of infertility male. Aim of this study is to study the association between depression and male infertility. Methods- 61 infertile men and 61 fertile men were randomly selected from DHH Kendrapada, Bhagabati hospital of Kendrapada and CHC of Derabish, Odisha and further administered HAM-D. Present study adopted case controlled design. Data analysis was done by using $\mathrm{R}$ statistical software. Results-Statistically significant association between depression and infertility men was found out $[\mathrm{p}<0.001]$. It has also been found out that the lower the age group, higher the depressive symptoms. Conclusion-Depression among infertile men is remarkably high and individuals with low age range are at higher risk of developing depression.
\end{abstract}

Keywords: Male infertility, Depressive symptoms, and Psychological factors associated with Infertility

Fertility is a relative rather than an absolute state, and comparatively few individuals are fully fertile. The majority fall somewhere in between these two extremes and the fertility of a marriage is a sum of fertilities of the partners. Low fertility in one can to some extent be balanced by high fertility in the other. Whereas low fertility in both partners may result in infertility (TaylorRobinson, 2008). Infertility is defined as the inability of a couple to achieve conception after one year of unprotected coitus. Sterility is an absolute state of inability to conceive. Secondary infertility or sterility is same states developing after an initial phase of fertility. All these conditions can affect either the male or female partner of a marriage.

\footnotetext{
${ }^{1}$ Assistant Professor, Dept of Clinical Psychology, Mental Health Institute, SCB MCH, Cuttack, India

${ }^{2}$ O\&G Specialist, District Headquater Hospital, Kendrapada, India

${ }^{3}$ Clinical Psychologist, Dept of Clinical Psychology, Mental Health Institute, SCB MCH, Cuttack, India

*Responding Author

(C) 2016, P Pattnaik, S Gharai, N Samantarav; licensee IJIP. This is an Open Access Research distributed under the terms of the Creative Commons Attribution License (http://creativecommons.org/licenses/by/2.0), which permits unrestricted use, distribution, and reproduction in any Medium, provided the original work is properly cited.
} 


\section{A Comparative Study and Association between Depression and Male Infertility}

Fertility also varies from time to time in the same individual. In the male these are not obvious except during childhood and, less absolutely in old age (School of Public Health \& Preventive Medicine, 2016). A man's fertility generally relies on the quality and quantity of his sperm (Zorn, 2007). Male infertility is diagnosed when, after testing both partners, reproductive problems have been found in the male.

It is estimated that one in 20 men has some kind of fertility problem with low numbers of sperm in his ejaculate (Zorn, 2007). Research indicates that most cases of fertility can be attributed to a physiological cause in the man or woman (Burns, 2007).

About one-third of the time a physiological problem is identified in the woman, one-third of the time in the male, and about one-tenth of the time in both partners. In another research $10 \%$ to $20 \%$ of cases (estimate vary), the basis of infertility cannot be determined. Research suggests that men and women differ in their psychological responses to infertility (Cousineau, 2007). Malik (2008) mentioned that men are in fact equally affected by the unfulfilled desire for a child but are less open about their feelings.

Men undergo various battles when facing personal infertility. These battles include anxiety concerning potency, masculinity and sexual adequacy. Apfel \& Keylor (2002) found that male infertility is an assault on a man's sense of self revives feelings of competition, castration and experiences of developmental trauma. Studies concerning such effects on infertile males are few in number and have come to the forefront in the past decade starting in 2001 even if the male partner is either the sole cause or a contributing cause of infertility in $40 \%$ of couples (Miall, 2008).

The diagnosis of infertility causes many males to question their masculinity; male factor infertility is frequently associated with high levels of stigma. For example, in a study exploring the views of fertile individuals towards infertile men and women, Miall (1994) found that male infertility was frequently seen as arising from sexual dysfunction and was associated with higher levels of stigma then female infertility. Many people assume that infertile men cannot perform sexually. This stigma adds to the heightened insecurities in infertile men. Male factor infertility is proposed to have such a social stigma that it produces stress and a culture of secrecy and protectiveness. Infertility is more difficult for female than the males. However, infertile men are likely to be depressive and anxious, and have low self-esteem, lower masculinity scores. Often, males do not show emotional stress in attempts to be the emotional stability within the relationship. Men cannot suppress such feelings for long periods of time without repercussions.

Less research has been done on men's reactions to infertility. Sometimes men's reactions may depend on whether they or their partners are diagnosed with infertility. When the problem is diagnosed in their wives or partners, men does not report being on distress as the women do. But 


\section{A Comparative Study and Association between Depression and Male Infertility}

when men learn that they are the ones who are infertile; they experience the same levels of low self-esteem, stigma, and depression as infertile women do (Harvard Mental Health Letter, 2009).

Most of the research in this area has been done in developed country; little attention has been paid to the psychological status of infertile men in a developing country like India.

\section{METHOD}

Aim And Objective:

The aim of this study is to evaluate the prevalence of depression among infertile male.

\section{Hypothesis}

1. There is a significant prevalence of depression among infertile male.

2. Depression will be more significant among the male aged 30-35 then other age range in infertile male.

\section{Research Design:}

Case controlled study design was adopted for the present research.

\section{Sample}

The experimental group, which consist of 61 infertile male were selected on the basis of simple random sampling from a frame of 112 infertile male from the O\&G OPD DHH Kendrapada, Bhagabati hospital of Kendrapada and CHC of Derabish, Odisha, India. The control group, which consist of 61 fertile male were also selected on the basis of simple random sampling from general population.

\section{Inclusion Criteria}

- Male who has the diagnosis of infertility

- All the sample aged between 30 to 44 years

- At least 3 years of marriage

- Employed with a minimum yearly income of 1lakh 20 thousand

\section{Exclusion Criteria}

- $\quad$ No alcohol or substance use

- $\quad$ No chronic physical illness

- $\quad$ No psychiatry history associated with the spouse

\section{Tools Used}

1-GHQ-The General Health Questionnaire-12[GHQ-12] designed by Goldberg[1972]. The GHQ has reasonable test retest reliability having both content validity and construct validity.

2-HAM-D-The Hamilton Depression [HAM-D]Rating Scale was developed by M.J. Hamilton[1960]. It' sreliability was found to be0.81 whereas validity was found to be $0.65-0.90$.

(c) The International Journal of Indian Psychology, ISSN 2348-5396 (e)| ISSN: 2349-3429 (p) | 65 


\section{A Comparative Study and Association between Depression and Male Infertility}

\section{Procedure}

The study was carried out in O\&G OPD, District Head Quarter Hospital, Kendrapada, Bhagabati hospital, Kendrapada \& CHC Derabish, Odisha. Initially 112 patients were included in the sampling frame for experimental group. Out of 112, seventy patients were randomly selected by fish-bowl method. After getting the consent from patients, HAM-D administered and GHQ was administered on spouse after getting high score on GHQ, nine samples has to be removed from the total sample. Then final study was done on 61 samples on experimental group. For control group randomly HAM-D \& GHQ had been given to 82 families with children. Then by fish-bowl method 61 samples were selected for the final study.

\section{Data Analysis:}

The data was statistically analysed by using R software.

\section{RESULTS}

Table-1: Showing Mean, SD and $t$ value representing significance of difference between control group and experimental group on the level of depression.

\begin{tabular}{|l|l|l|l|}
\hline Group & Mean & \multicolumn{1}{|c|}{ SD } & P value \\
\hline Control group & 4.11 & 5.08 & 1.73e-05* \\
\hline Experimental group & 0.92 & 2.25 & \\
\hline
\end{tabular}

$* \mathrm{P}<0.001$ level

The t value on above table show that significant difference exist between the control group and the experimental group $[\mathrm{P}<0.001$ level].

\section{Figure1}

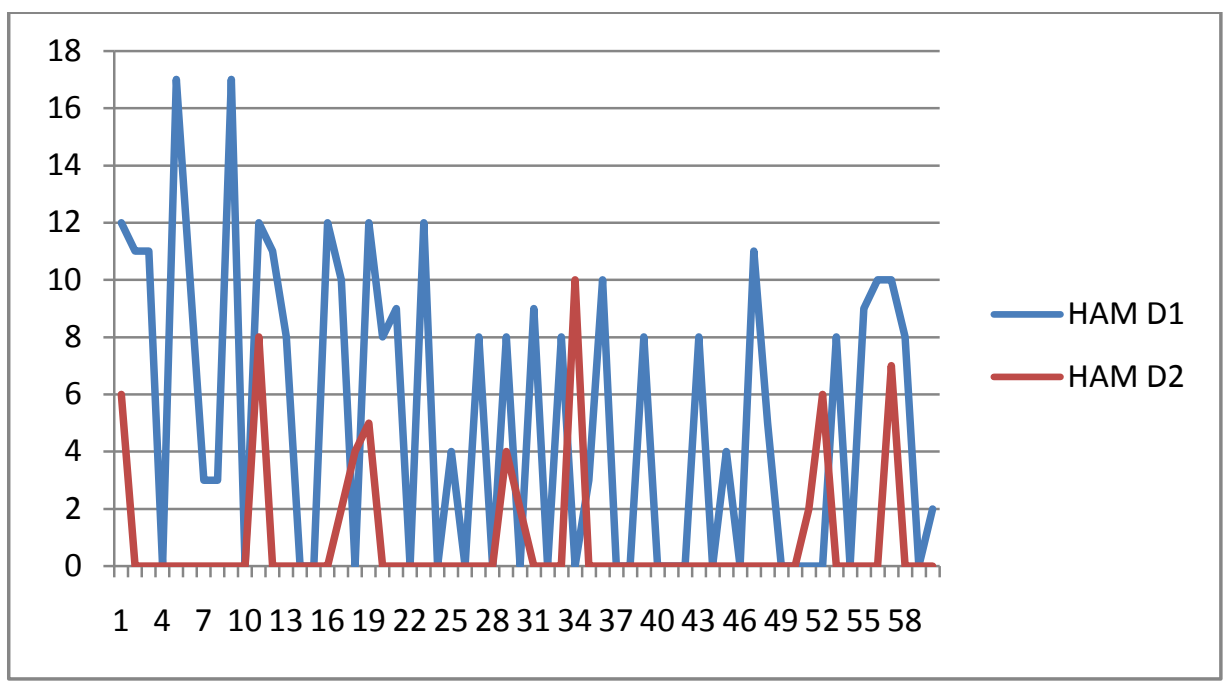

HAM D1-Scores of control group. HAM D2-Scores of experimental group 
A Comparative Study and Association between Depression and Male Infertility

Table-2: Showing depression on various age range of control group

\begin{tabular}{|l|l|l|}
\hline Age group & Frequency & Percentage \\
\hline $30-34$ & 18 & 29 \\
\hline $35-39$ & 7 & 11 \\
\hline $40-44$ & 3 & 5 \\
\hline
\end{tabular}

The percentage showing above indicates that people in the age range 30-34 were more depressed followed by 35-39 age group.

Figure 2

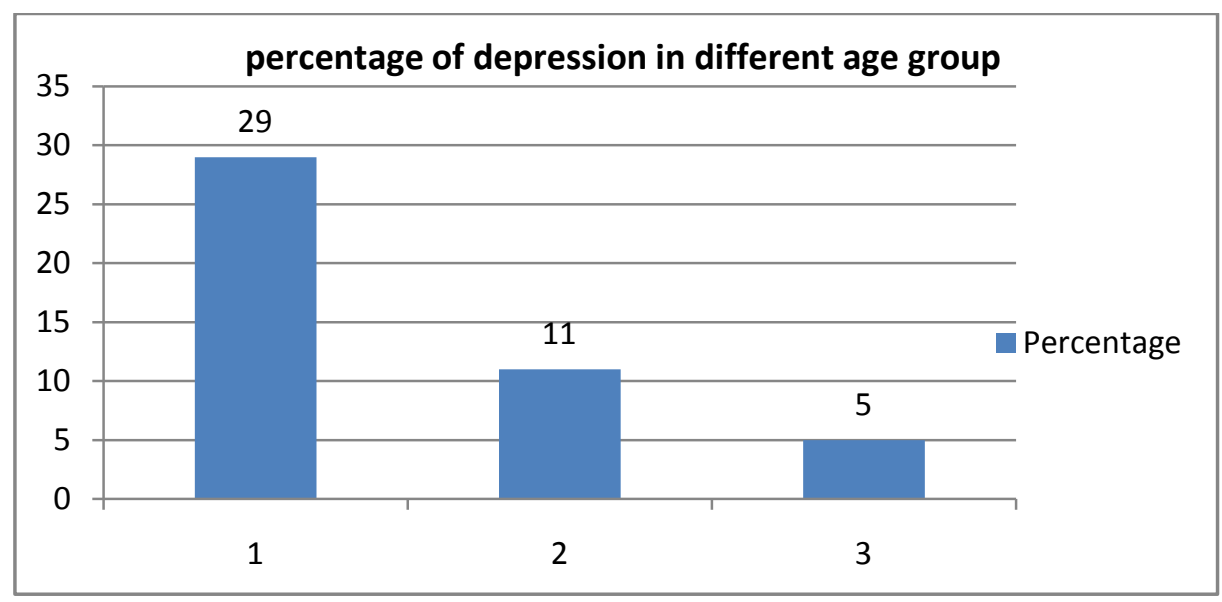

\section{DISCUSSION}

Couple struggling with infertility faces a wide range of emotional and mental health concerns. Most people assume that they will be able to procreate, the vast majority of husbands and wives were taken by total surprise when they became aware of their infertility (Greil, 1991). Male factor infertility is proposed to have such social stigma that it produces much negative social stress, and a culture of secrecy and protectiveness (Peronace, Boivin \& Schmidt, 2007).

Individuals who learn they are infertile often experience the normal but nevertheless distressing emotions common to those who are grieving any other significant loss. There are typical reactions that include shock, grief, depression, anger, and frustration as well as loss of selfesteem, self-confidence and a sense of control over one's destiny. In comparison to patient with other medical conditions, psychological symptoms associated with infertility are similar to those related to cancer, hypertension and cardiac rehabilitation (Allayassin et.al, 2011).

Results in the current study indicate that there is a significant difference between the infertile male and fertile male in the level of depression. Men's initial reaction was shock when they find out they are infertile. There is still a common but incorrect belief that infertility is a woman's problem. Therefore when men are told there is a sperm problem, they are often unprepared. 


\section{A Comparative Study and Association between Depression and Male Infertility}

Being told that there is a sperm problem can affect a men's sense of masculinity, sexuality and potency. Ahmadi et al. (2011) in a study on infertile men found out that about $42.9 \%$ of infertile men have a diagnosis of depression.

Further the finding in current study suggests that the lower the age of the subject more was the depression. It might be due to the fact that as a person grows old, he may develop certain coping strategies to cope with stress. In a Patriarchal society like India men has plays an important role. So male infertility represents a profoundly threatening and emasculating problem which causes a great deal of psychological distress.

\section{CONCLUSION}

The findings of the present study have been supported by various research works and literatures. Like many infertile female, many men do suffer from depression when they diagnosed with infertility. Many patients find a way to cope on their own, or they seek support from friends, family. But other need additional help like short term counselling, specific type of therapy like interpersonal therapy and cognitive behaviour therapy can give relief to infertile patients suffering from mild to moderate depression.

\section{Acknowledgments}

The author appreciates all those who participated in the study and helped to facilitate the research process.

\section{Conflict of Interests}

The author declared no conflict of interests.

\section{REFERENCES}

Ahmadi, H., Montaser-Kouhsari, L., Nowroozi, M. R., \& Bazargan-Hejazi, S. (2011). Male infertility and depression: a neglected problem in the Middle East. The journal of sexual medicine, 8(3), 824-830.

Apfel, R. J., \& Keylor, R. G. (2002). Psychoanalysis and infertility myths and realities. The International Journal of Psychoanalysis, 83(1), 85-104.

Burns LH. "Psychiatric Aspects of Infertility and Infertility Treatments," Psychiatric Clinics of North America (Dec. 2007): Vol. 30, No. 4, pp. 689-716.

Conrad, R., Schilling, G., Langenbuch, M., Haidl, G., \& Liedtke, R. (2001). Alexithymia in male infertility. Human Reproduction, 16(3), 587-592.

Cousineau TM, et al. "Psychological Impact of Infertility," Best Practice \& Research: Clinical Obstetrics and Gynaecology (April 2007): Vol. 21, No. 2, pp. 293-308.

Drosdzol, A., \& Skrzypulec, V. (2009). Depression and anxiety among Polish infertile couplesan evaluative prevalence study. Journal of Psychosomatic Obstetrics \& Gynecology, 30(1), 11-20.

Harvard Mental Health Letter, (2009), Retrieved from; 


\section{A Comparative Study and Association between Depression and Male Infertility}

http://www.health.harvard.edu/newsletter_article/The-psychological-impact-ofinfertility-and-its-treatment

Inhorn, M. C. (2004). Middle Eastern masculinities in the age of new reproductive technologies: male infertility and stigma in Egypt and Lebanon. Medical Anthropology Quarterly, 18(2), 162-182.

Keylor, R., \& Apfel, R. (2010). Male infertility: integrating an old psychoanalytic story with the research literature. Studies in Gender and Sexuality, 11(2), 60-77.

Khademi, A., Alleyassin, A., Aghahosseini, M., Ramezanzadeh, F., \& Abhari, A. A. (2005). Pretreatment Beck Depression Inventory score is an important predictor for posttreatment score in infertile patients: a before-after study. BMC psychiatry, 5(1), 1.

Malik, S. H., \& Coulson, N. (2008). The male experience of infertility: a thematic analysis of an online infertility support group bulletin board. Journal of reproductive and infant psychology, 26(1), 18-30.

Malik, Sumaira H. and Neil Coulson. "The male experience of infertility: a thematic analysis of an online infertility support group bulletin board." Journal of Reproductive and Infant Psychology 26. (2008): 18-30.

Miall, C. E. (1994). Community constructs of involuntary childlessness: Sympathy, stigma, and social support. Canadian Review of Sociology/Revue canadienne de sociologie, 31(4), 392-421., 31(4), 392-421.,

Miall, Charlene E. "Community constructs of involuntary childlessness: Sympathy, stigma, and social support.” Canadian Review of Sociology 31. (2008): 392-421.

Peronace, L. A., Boivin, J., \& Schmidt, L. (2007). Patterns of suffering and social interactions in infertile men: 12 months after unsuccessful treatment. Journal of Psychosomatic Obstetrics \& Gynecology, 28(2), 105-114.

School of Public Health \& Preventive Medicine (2016), Retrieved from; https:// www.andrologyaustralia.org/your-health/male-infertility/

Taylor-Robinson, T. (Ed.). (2012). Clinical Problems in Sexually Transmitted Diseases (Vol. 11). Springer Science \& Business Media.

The Practice Committee of the American Society for Reproductive Medicine. "Child-Rearing Ability and the Provision of Fertility Services," Fertility and Sterility (Sept. 2004): Vol. 82, Suppl. 1, pp. S208-11.

Wischmann, T., Scherg, H., Strowitzki, T., \& Verres, R. (2009). Psychosocial characteristics of women and men attending infertility counselling†. Human Reproduction, 24(2), 378-385

Zorn, B., J. Auger, V. Velikonja, M. Kolbezen, and H. Meden-Vrtovec. "Psychological factors in male partners of infertile couples: relationship with semen quality and early miscarriage." International Journal of Andrology 0105-6263. (2007): 557-564.

How to cite this article: P Pattnaik, S Gharai, N Samantarav (2016), A Comparative Study and Association between Depression and Male Infertility, International Journal of Indian Psychology, Volume 3, Issue 4, No. 66, ISSN 2348-5396 (e), ISSN: 2349-3429 (p), DIP:18.01.160/20160304, ISBN: 978-1-365-39396-9 